\title{
A combined experimental and theoretical study of methyl acetoacetate adsorption on $\mathrm{Ni}\{100\}$
}

Article

Accepted Version

Tsaousis, P., Ontaneda, J., Bignardi, L., Bennett, R. A., GrauCrespo, R. and Held, G. (2018) A combined experimental and theoretical study of methyl acetoacetate adsorption on $\mathrm{Ni}\{100\}$. The Journal of Physical Chemistry C, 122 (11). pp. 6186-6194. ISSN 1932-7447 doi: https://doi.org/10.1021/acs.jpcc.8b00204 Available at https://centaur.reading.ac.uk/75985/

It is advisable to refer to the publisher's version if you intend to cite from the work. See Guidance on citing.

Published version at: http://dx.doi.org/10.1021/acs.jpcc.8b00204

To link to this article DOI: http://dx.doi.org/10.1021/acs.jpcc.8b00204

Publisher: American Chemical Society

All outputs in CentAUR are protected by Intellectual Property Rights law, including copyright law. Copyright and IPR is retained by the creators or other copyright holders. Terms and conditions for use of this material are defined in the End User Agreement.

www.reading.ac.uk/centaur 
Central Archive at the University of Reading

Reading's research outputs online 


\section{A Combined Experimental and Theoretical}

\section{Study of Methyl Acetoacetate Adsorption on}

\section{$\mathrm{Ni}\{100\}$}

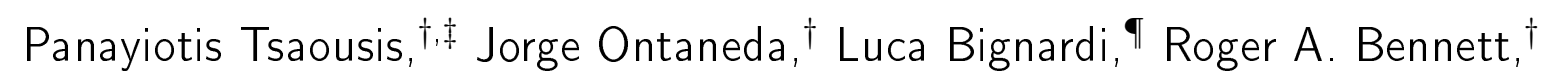
Ricardo Grau-Crespo, ${ }^{*, \dagger}$ and Georg Held*,,,$\ddagger$

$\dagger$ Department of Chemistry, University of Reading, Reading RG6 6AD, UK

$\ddagger$ Diamond Light Source Harwell Science and Innovation Campus, Didcot OX11 OQX, UK

\Elettra - Sincrotrone Trieste S.C.p.A., 34149 Trieste, Italy

E-mail: r.grau-crespo@reading.ac.uk; g.held@reading.ac.uk 


\begin{abstract}
The enantio-selective hydrogenation of methyl acetoacetate (MAA) over modified Ni-based catalysts is a key reaction in the understanding of enantioselective heterogeneous catalysis as it represents the only example of this class of reactions catalysed by base metals. Yet, there is very little molecular-level information available about the adsorption complex formed by the reactants on Ni surfaces. Here, we report a combined experimental and theoretical study of the adsorption of MAA on the $\mathrm{Ni}\{100\}$ surface. X-ray photoelectron spectroscopy shows that MAA forms stable multilayers at low temperatures, which desorb between $200 \mathrm{~K}$ and $220 \mathrm{~K}$. At higher temperatures a single chemisorbed layer is formed, which decomposes between $300 \mathrm{~K}$ and $350 \mathrm{~K}$. Density functional theory modelling predicts an enolate species with bidentate coordination as the most stable chemisorbed species. Comparison of photoelectron spectroscopy and X-ray absorption data with simulations using this adsorption model show good qualitative and quantitative agreement. The molecular plane is tilted with respect to the surface plane by about $50^{\circ}$. This breaking of symmetry provides a mechanism for the enantio-selective hydrogenation.
\end{abstract}

\title{
Introduction
}

The hydrogenation of $\beta$-ketoesters over modified Raney nickel opens up a pathway into enantioselective heterogeneous catalysis of bio-related molecules. Much of the characterisation of this reaction in terms of kinetics, modifier and solvent dependence was done by Izumi and coworkers in the 1960's. ${ }^{1,2}$ The quantitative characterization at the molecular scale and the understanding of chiral and chirally-modified surfaces of model catalysts experienced a rapid growth over the last two decades, driven by the refinement of experimental surface characterization techniques and theoretical modelling. ${ }^{3-6}$ This progress has also been driven by the increasing demand for enantiopure chemicals in drug manufacturing, where homogeneous catalytic processes are predominantly used. ${ }^{7}$ However, the subsequent phase 
separation necessary in homogeneous catalysis is difficult and generally expensive. The use of heterogeneous catalysts avoids this problem; therefore, viable heterogeneous routes would make the production of pharmaceuticals greener and more economical.

In the case of one of the simplest $\beta$-ketoesters, methyl acetoacetate, $\mathrm{CH}_{3}-\mathrm{O}-\mathrm{C}(\mathrm{O})-\mathrm{CH}_{2}-\mathrm{C}(\mathrm{O})-\mathrm{CH}_{3}$, (MAA, see Fig. 1), the hydrogenation results in a racemic mixture of the $R$ and $S$ methyl-3-hydroxybutyrate (MHB) when carried out over an unmodified Raney Ni catalyst. However, the modification of the catalyst with chiral $\alpha$-amino acids or $\alpha$-hydroxy acids leads to high enantiomeric excess, up to $86 \%$. (R)-hydroxy acids (such as (R,R)-tartaric acid) or (S)-amino acids (such as (S)-glutamic acid) modifiers will produce (R)-product in excess, while (S)-hydroxy and (R)-amino-acid modifiers will generate (S)-products in excess. ${ }^{2,6}$ The reaction is well-characterized in terms of enantiomeric excess, temperature and solvent dependencies. ${ }^{1,8-10}$ Izumi et al. suggested that the surface modification is due to a combination of modifier and solvent molecules since the solvent has a significant influence on the enantiomeric excess and corrosion of the catalyst. Furthermore, they showed that the enantioselective behavior depends on how the reactant MAA adsorbs on the Ni surface and how it interacts with the modifier rather than on the transition state of the hydrogenation reaction. Hence, determining the adsorption geometry of MAA at the molecular level and the influence modifiers have on it is a key step to understand and optimize the enantioselective behavior of Ni-based catalysts. 


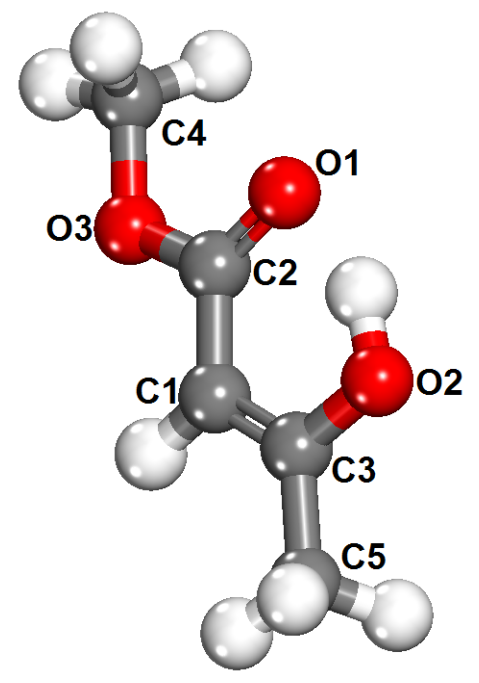

Figure 1: Molecular structure of MAA enol, which was found to be the most stable MAA tautomer in gas phase in Ref. ${ }^{11}$

On close-packed single crystal surfaces of many coinage and Pt-group metals chiral modifiers and/or reactants often form ordered adsorbate layers with well-defined chemical environments under UHV conditions. On Ni surfaces, such ordered structures are rare. Therefore little quantitative molecular-scale information is available on reactants and modifiers of enantioselective reactions on these surfaces. Raval and coworkers studied the adsorption of tartaric acid on $\mathrm{Ni}\{110\}$ and showed that the interaction with the modifier caused a chiral reconstruction of the surface. ${ }^{12-14}$ Our group has studied the adsorption of alanine on Ni\{111\} using XPS and near-edge X-ray absorption fine structure (NEXAFS) spectroscopy. ${ }^{15}$ In this and earlier studies, the combination of these two experimental techniques has proved very powerful for characterising the adsorption complex in terms of chemical state, bond coordination, and molecular orientation. ${ }^{15-19}$ These experimental and theoretical studies ${ }^{10,12,14,15,20-22}$ show that the behavior of amino acid modifiers on Ni differs significantly from that on $\mathrm{Cu}$ surfaces. ${ }^{23,24} \mathrm{On} \mathrm{Cu}$ deprotonated anionic species dominate with adsorption geometries exhibiting a typical tridentate "OON" footprint. In the $\mathrm{Ni}$ case anionic adsorption species are found to be coadsorbed with zwitterionic species which is more comparable with the situation on $\operatorname{Pd}\{111\}$ surfaces. ${ }^{25,26}$ 
The adsorption of MAA and several modifiers, including tartaric acid and glutamic acid, on $\mathrm{Ni}\{111\}$ was studied by Baddeley's group using temperature-programmed desorption (TPD), IR spectroscopy and scanning tunneling microscopy (STM). There, the spatial configuration between the modifiers and the substrate depends on the coverage and adsorption temperature. Evidence was found for a one-to-one interaction between the chiral modifiers and MAA. In addition, it was shown that the experimental conditions, in particular temperature, influence the keto-to-enol ratio of MAA. ${ }^{10,20,21,27-29}$ Recently, our group combined XPS and NEXAFS with DFT modelling to study the adsorption complex of MAA on $\mathrm{Ni}\{111\}$. We found that the reactant MAA adsorbs on a flat surface forming deprotonated enolate species with bidentate coordination. The formation of energetically more favourable adatom adsorption complexes is kinetically hindered at low temperatures. ${ }^{11}$ To our knowledge, no detailed study exists for MAA adsorbed on the $\mathrm{Ni}\{100\}$ surface. The present study provides experimental data and theoretical modelling characterising the adsorption complex of MAA on $\mathrm{Ni}\{100\}$.

\section{Methodology}

\section{Experimental Methods}

The XPS and NEXAFS experiments were performed in the Elettra synchrotron in Trieste (Italy) in the UHV endstation of the SUPERESCA beamline, which provides a horizontally polarized X-ray beam. The base pressures in the preparation and analysis chamber were in the $10^{-10}$ mbar and $10^{-11}$ mbar range, respectively. Sample cleaning was achieved by cycles of sputtering $\left(3 \times 10^{-6} \mathrm{mbar} / 1-1.5 \mathrm{kV}\right)$ and oxygen treatment $\left(1 \times 10^{-8} \mathrm{mbar}\right.$ for $1 \mathrm{~min}$ at room temperature with subsequent annealing to $900 \mathrm{~K}$ ). Sample cleanliness was confirmed by XPS and LEED. The Ni single crystal was mounted at the base of the a liquid nitrogencooled cold finger and could be heated indirectly by a filament mounted close to the back face of the sample. Its temperature was measured through a spot-welded thermocouple and 
controlled using a programmable temperature controller. MAA was dosed via a leak valve. Prior to dosing, the liquid was purified by means of freeze-thaw cycles, until no bubbles were observed during thawing (4 cycles). A pressure rise to the low $10^{-9}$ mbar range was observed during dosing of the molecule in the preparation chamber. Due to the small rise in pressure and differences in pumping speed, there was no good correlation between dosing time and surface coverage, hence the coverage was determined by XPS (see below).

The XP spectra were acquired in the $\mathrm{C} 1$ s region $(h \nu=400 \mathrm{eV})$ and $\mathrm{O} 1$ s region $(h \nu=$ $650 \mathrm{eV}$ ) using pass energies of $5 \mathrm{eV}$ and $15 \mathrm{eV}$, which resulted in combined resolution of beamline and analyser of $0.22 \mathrm{eV}$ and $0.25 \mathrm{eV}$, respectively. Spectra of the Fermi edge were obtained every time the monochromator was moved, for calibrating the offset of the binding energy axis. The spectra were normalized at low binding energy and the background was subtracted for quantitative analysis. The coverage (in ML) was calibrated by comparing O 1s spectra measured with a photon energy of $h \nu=1000 \mathrm{eV}$ with those of CO adsorbed to saturation at room temperature $\left(0.5 \mathrm{ML}\right.$, i.e. 1 molecule per 2 surface Ni atoms). ${ }^{30}$ Temperature-programmed XPS data were recorded by heating the sample at a constant rate of $12 \mathrm{~K} \mathrm{~min}^{-1}$ in front of the analyzer while measuring alternating $\mathrm{C}$ 1s and $\mathrm{O}$ 1s spectra $(\sim 15 \mathrm{~s} /$ spectrum $)$.

NEXAFS spectra were acquired in the O K-edge region detecting O KLL Auger electrons with kinetic energies of $507 \mathrm{eV}$. Three angles of incidence were used for determining the orientation of MAA on surface: $\theta=0^{\circ}$ (normal incidence), $35^{\circ}$ and $70^{\circ}$, where $\theta$ refers to the angle between the electric field vector and the surface plane. The photon energy was calibrated using the $\pi^{*}$-resonance in CO NEXAFS spectra. ${ }^{31}$ The spectra were corrected for the transmission of the beamline through dividing by the photon flux, $I_{0}$, which was collected using the drain current of last refocusing mirror. Spectra of the clean surface, corrected in the same way, were subtracted as background. Finally, the spectra were normalized at $565 \mathrm{eV}$, which is above all oxygen absorption resonances. 


\section{Computational Methods}

Density functional theory (DFT) calculations were performed using plane-wave basis sets as implemented in VASP. ${ }^{32,33}$ Following the approach of previous DFT investigations of molecular adsorption on this surface, ${ }^{34,35}$ the $\mathrm{Ni}\{100\}$ surface was modeled with a periodic slab of 4 atomic layers. This has proved to yield well converged results for adsorption energies and geometries. ${ }^{36}$ Only the two uppermost Ni layers were fully relaxed, while the two bottom layers were fixed in their bulk positions. This procedure has often been found to accelerate the convergence of calculated surface properties with respect to the thickness of the simulation slab. ${ }^{37,38} \mathrm{~A}$ vacuum gap of $12 \AA$ was included above the surface in order to avoid interactions between periodic cells. Laterally, the supercell consisted of $(5 \times 5)$ surface unit cells, which corresponds to a surface coverage of $0.04 \mathrm{ML}$ (one molecule per 25 surface $\mathrm{Ni}$ atoms) when only one adsorbed molecule is included in each supercell, as we did in this study. As nickel is a ferromagnetic metal, all calculations included spin polarization.

The projected augmented wave (PAW) method ${ }^{39,40}$ was used to describe the interaction between the valence and core electrons. The number of plane waves in the slab calculations was limited by a kinetic energy cutoff of $400 \mathrm{eV}$, which is the recommended value for the employed PAW potentials. Monkhorst-Pack grids ${ }^{41}$ with a maximum separation of $0.15 \AA^{-1}$ between $k$-points were used for sampling the Brillouin-zone. This grid density, which was found sufficient for convergence of the bulk Ni total energy, corresponds to a $4 \times 4 \times 1$ grid for the reciprocal space of the slab model. The threshold for forces on the $\mathrm{Ni}$ ions during geometry optimizations was set to $0.02 \mathrm{eV} \AA^{-1}$. In order to compensate for the use of an asymmetric slab, all simulations included a dipole correction as implemented in VASP, based on a method proposed by Makov and Payne. ${ }^{42}$ Isolated molecules of MAA in the gas phase were simulated as reported in our previous work. ${ }^{11}$

We used a functional based on the generalized gradient approximation (GGA) in the

form of the revised Perdew-Burke-Ernzerhof (revPBE) exchange-correlation functional. ${ }^{43}$ In order to account for van der Waals (vdW) interactions, we used the DFT-D3 method with 
Becke-Jonson (BJ) damping. ${ }^{44,45}$ This combination of functional and dispersion correction has been shown to provide a very robust description of vdW effects in comparison with other GGA-based formulations ${ }^{46}$ and was used successfully in our previous study of MAA on $\mathrm{Ni}\{111\}$.

The configurational space of adsorption was explored by considering a variety of initial positions of MAA onto the surface. Both tautomeric forms of the molecule were considered as well as deprotonated surface species. For each final stable adsorption configuration, we calculated the adsorption energy $E_{\text {ads }}^{\mathrm{DFT}}$ as follows:

$$
E_{\text {ads }}^{\mathrm{DFT}}=E_{\text {slab }+ \text { molecule }}-\left(E_{\text {slab }}+E_{\text {molecule }}\right)
$$

where $E_{\text {slab+molecule }}$ represents the ground-state energy of the optimized substrate-adsorbate system, $E_{\text {slab }}$ corresponds to the energy of the relaxed clean $\mathrm{Ni}\{100\}$ surface, and $E_{\text {molecule }}$ denotes the energy of the MAA molecule in the gas phase, in the lowest-energy tautomeric configuration.

The effect of zero-point energy (ZPE) on the adsorption energy was estimated by calculating the vibrational frequencies of the adsorbed molecule (keeping the atoms of the metal surface frozen) and the frequencies of the gas phase molecule, using a finite-difference method. The ZPE values, i.e. half the sum of the vibrational frequencies in each case, were then added to the groundstate energies $E_{\text {slab+molecule }}$ and $E_{\text {molecule, }}$ respectively, in equation (1). This approach assumes that adsorption does not alter significantly the vibrational modes of the heavy metal atoms at the surface.

In order to compare the modelling results with XPS data we calculated core-level shifts in the so-called final-state approximation, ${ }^{47}$ where the shifts are obtained as total energy differences between two separate calculations as reported in Ref. ${ }^{48}$ Previous work has shown that this computational methodology gives relative core level shifts in excellent agreement with experiment. ${ }^{48-50}$ The method does not yield correct absolute values for the core level binding energies; ${ }^{48}$ we therefore consider core level shifts, $\Delta B E_{\mathrm{CL}}(A)$, instead. These are 
defined as the difference in binding energy of specific core-electrons $B E_{\mathrm{CL}}$ between an atom $A$ and a reference atom $A_{\text {ref: }}$

$$
\Delta B E_{\mathrm{CL}}(A)=B E_{\mathrm{CL}}(A)-B E_{\mathrm{CL}}\left(A_{\text {ref }}\right)
$$

Compared to the $\mathrm{O}$ 1s case, the agreement between the simulated $\mathrm{C}$ 1s spectra and the experiment was significantly worse (see Supporting Information for further details). This is in agreement with previous findings on similar systems ${ }^{11,51}$ and is not fully understood yet. Nevertheless, there is little variation in the calculated $\mathrm{C}$ 1s binding energies between different adsorption geometries, as none of the carbon atoms is involved in any surface bond. We therefore, base our discussion on the relative shifts of the $\mathrm{O}$ 1s levels of the oxygen atoms within the MAA molecule, which are more affected by the adsorption configuration on the $\mathrm{Ni}\{100\}$ surface. In all cases we chose as reference atom the one yielding the lowest $\mathrm{O}$ 1s binding energy. In order to allow a visual comparison between experimental and theoretical data, spectra were modelled by sums of Gaussians with equal width (FWHM $1.5 \mathrm{eV}$ ) and height, centered at the respective binding energy shifts.

\section{Results}

\section{X-Ray Photoelectron Spectroscopy Results}

Figure 2 shows C 1s and O 1s XPS spectra of MAA on Ni\{100\}. The spectra were obtained after dosing MAA at $180 \mathrm{~K}$ for $1 \mathrm{~min}$ and $3 \mathrm{~min}$, which led to coverages of 0.22 and $0.23 \mathrm{ML}$, respectively, and at $100 \mathrm{~K}$ for $6 \mathrm{~min}$, which led to the growth of a "multilayer". Based on the modelling results (see below), it was estimated that a MAA molecule would block about $6 \mathrm{Ni}$ atoms, i.e. the saturation coverage of the chemisorbed layer is around 0.17 ML. Above

this value the coverage calibration by XPS is not linear anymore, as molecules in the second and higher layers attenuate the signal from the molecules below. This also depends on the 
growth kinetics / speed of growth and thus explains the differences between the $0.22 \mathrm{ML}$ and 0.23 ML spectra despite the small difference in nominal coverage.

The $\mathrm{O}$ 1s spectra, for $0.22 \mathrm{ML}$ (Fig.2.b) show two resolved peaks at $\sim 531.3 \mathrm{eV}$ and $533.2 \mathrm{eV}$ with an area ratio of $0.7: 1$. The low BE peak (peak A) can be attributed to deprotonated oxygen in contact with the nickel surface, ${ }^{15}$ while the peak at $533.2 \mathrm{eV}$ (B) is related to oxygen atoms detached from the surface. The latter peak in the $\mathrm{O}$ 1s region broadens towards lower binding energies with increasing coverage, indicating the onset of multilayer formation. When the coverage increases and a thicker multilayer is formed, a third peak at $532.6 \mathrm{eV}$ (C) can be resolved which is linked to the multilayer species. This species could be a protonated oxygen, implying the coexistence of two species of MAA in the multilayer regime.

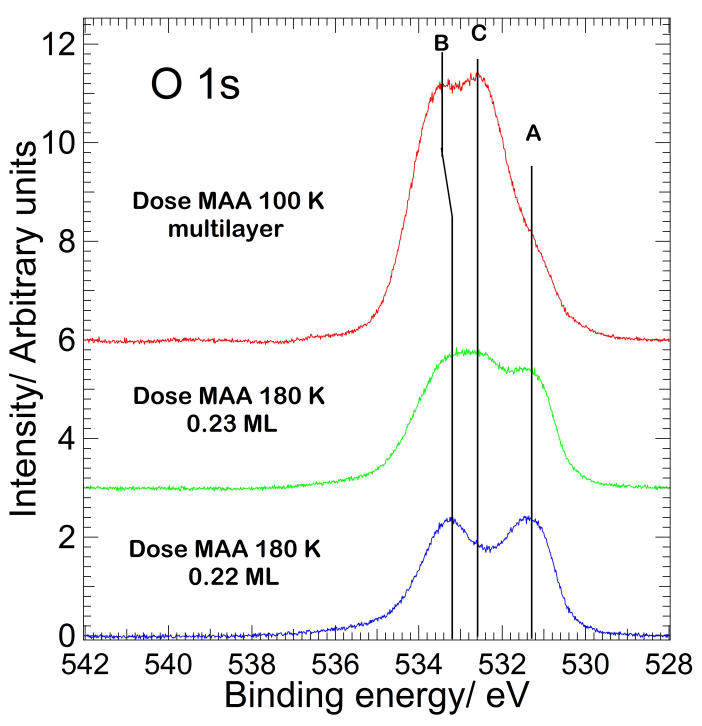

(a)

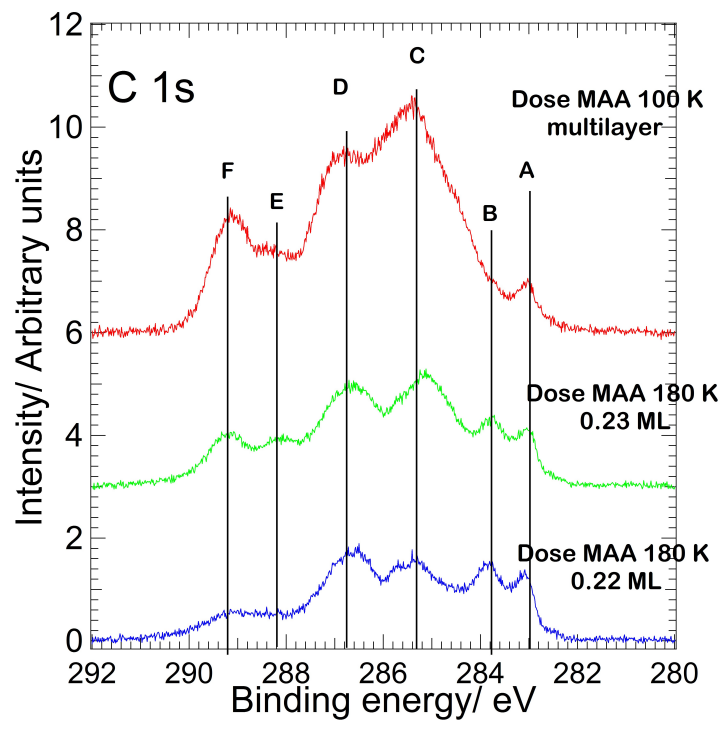

(b)

Figure 2: XPS spectra of MAA dosed onto $\mathrm{Ni}\{100\}$ at the indicated temperatures, in the (a) $\mathrm{C} 1 \mathrm{~s}(h \nu=400 \mathrm{eV})$ and (b) $\mathrm{O} 1 \mathrm{~s}$ regions $(h \nu=650 \mathrm{eV})$

In the $\mathrm{C}$ 1s region (Fig. 2.a) we can detect six peaks at $283.0 \mathrm{eV}(\mathrm{A}), 283.8 \mathrm{eV}(\mathrm{B})$, $285.3 \mathrm{eV}(\mathrm{C}), 286.8 \mathrm{eV}(\mathrm{D}), 288.2 \mathrm{eV}(\mathrm{E})$ and $289.2 \mathrm{eV}(\mathrm{F})$. Following previous work, ${ }^{15}$ the two peaks at the lowest binding energies (peak A and B) are associated with dissociation products of the MAA molecule. The remaining peaks are associated with intact MAA. Us- 
ing calculated core-level shifts from DFT (see Table S2 in Supporting Information) the XPS signal 285-287 eV (peaks C and D) is assigned, in order of increasing BE, to the convoluted lines of $\mathrm{C} 1(\mathrm{C} 2=\underline{\mathrm{C}} 1=\mathrm{C} 3), \mathrm{C} 5\left(\mathrm{C} 3-\underline{\mathrm{C}} 5 \mathrm{H}_{3}\right), \mathrm{C} 3(\mathrm{C} 1=\underline{\mathrm{C}} 3(-\mathrm{O} 2)-\mathrm{C} 5), \mathrm{C} 4\left(\mathrm{H}_{3} \underline{\mathrm{C}} 4-\mathrm{O} 3\right)$ and $\mathrm{C} 2$ $(\mathrm{O} 3=\underline{\mathrm{C} 2}(-\mathrm{O} 1)=\mathrm{C} 1)$ of the chemisorbed molecule (see also Fig S3 in Supporting Information). The two peaks at high binding energies (E and F) are most likely multilayer and/or satellite features.

Figures 3.a and 3.b show temperature-programmed (TP-)XPS data after dosing MAA on $\mathrm{Ni}\{100\}$ for $3 \mathrm{~min}$ at $180 \mathrm{~K}(0.23 \mathrm{ML})$ while Figures 3.c and 3.d show spectra of a MAA multilayer adsorbed at $100 \mathrm{~K}$ (3 min dose). The TP-XPS data are normalized at the low binding side without background subtraction, while the spectra in Figures 3.c,d have the background subtracted. Multilayer desorption occurs around 200 - $220 \mathrm{~K}$, indicated by the disappearance of the peaks at $288.2 \mathrm{eV}$ and $289.2 \mathrm{eV}$ in the $\mathrm{C} 1$ s region (Figs 3.a,c; peaks E and $\mathrm{F}$ ) and $532.6 \mathrm{eV}$ in the $\mathrm{O}$ 1s region (Fig. 3.b,d; peak C), as well as by the shift of peak $\mathrm{B}$ in the $\mathrm{O}$ 1s region (Fig. 3.d) to low binding energies. Above $200 \mathrm{~K}$ we can observe a clear splitting of peak $\mathrm{C}$ in the $\mathrm{C} 1$ s region and the appearance of a new peak at $284.5 \mathrm{eV}$ (indicated by an arrow in Fig. 3.c), which is assigned to the $-\mathrm{C} 3-\underline{\mathrm{C} 1}=\mathrm{C} 2-$ species. Heating from $300 \mathrm{~K}$ (0.21 ML) to $330 \mathrm{~K}(0.19 \mathrm{ML})$, causes a significant reduction of the signal corresponding to the intact molecule in both regions, accompanied by an increase in signal at $283.0 \mathrm{eV}$ (peak A) in the $\mathrm{C} 1 \mathrm{~s}$ region. This peak is associated with decomposition products, most likely atomic carbon. At $340 \mathrm{~K}$ we observe a significant shift of peak $\mathrm{B}$ in the $\mathrm{O}$ 1s region $(\mathrm{O}$ atoms not bound to the Ni surface) to lower BE (from $533.2 \mathrm{eV}$ to $533.0 \mathrm{eV}$, Fig.3.d). At this point the coverage is close to the saturation coverage $(0.16 \mathrm{ML})$ and the intensity ratio between the $\mathrm{O}$ 1s peaks $\mathrm{A}(\mathrm{O}$ atoms in contact with $\mathrm{Ni})$ and $\mathrm{B}(\mathrm{O}$ atoms not in contact with $\mathrm{Ni}$ ) is $1.9: 1$, which indicates that MAA forms a bond with the $\mathrm{Ni}\{100\}$ surface through two oxygen atoms in a bidentate geometry. Above $350 \mathrm{~K}$ MAA is fully dissociated, leaving only decomposition fragments on the surface. 


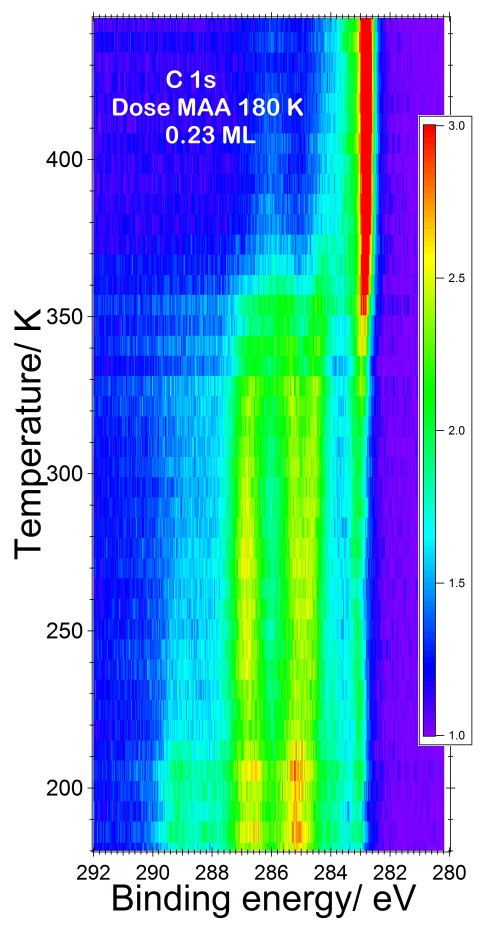

(a)

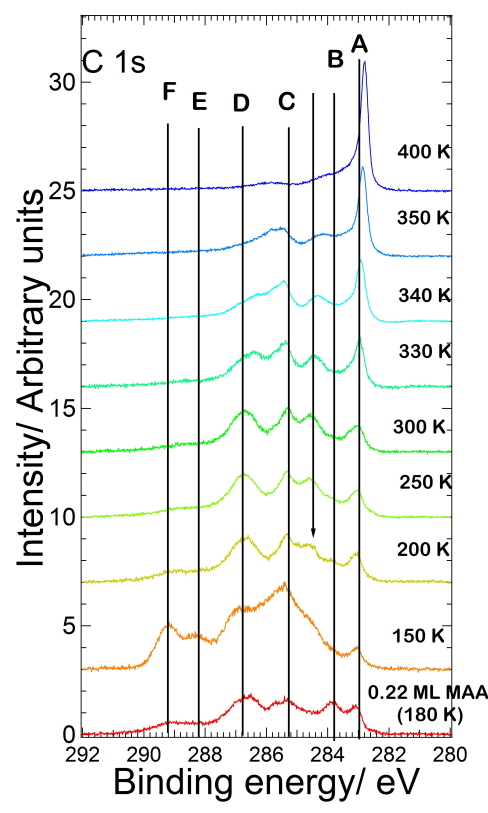

(c)

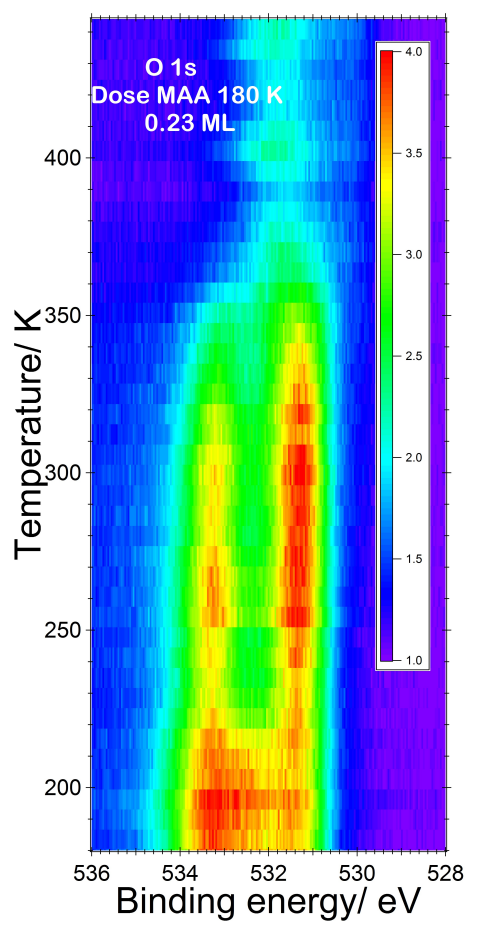

(b)

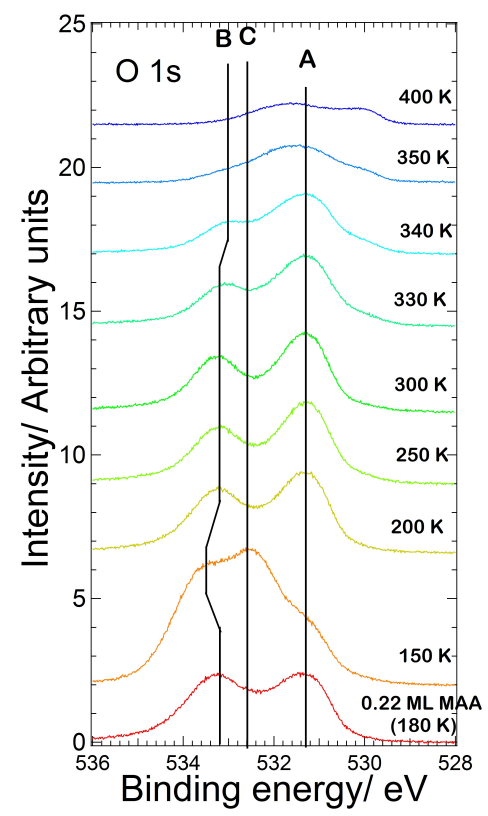

(d)

Figure 3: Temperature-dependent XPS spectra of MAA on Ni\{100\}: TP-XPS of the (a) $\mathrm{C} 1 \mathrm{~s}$ and (b) $\mathrm{O} 1 \mathrm{~s}$ regions $(h \nu=650 \mathrm{eV})$ after dosing MAA on $\mathrm{Ni}\{100\}$ at $180 \mathrm{~K}$ for $3 \mathrm{~min}$ (heating rate $\left.12 \mathrm{~K} \mathrm{~min}^{-1}\right)$; (c) $\mathrm{C} 1 \mathrm{~s}(h \nu=400 \mathrm{eV})$; (d) O $1 \mathrm{~s}(h \nu=650 \mathrm{eV})$ XPS spectra after dosing MAA at $100 \mathrm{~K}$ for $3 \mathrm{~min}$ and stepwise annealing as indicated. 


\section{NEXAFS Results}

Figure 4 shows angle dependent NEXAFS spectra after dosing MAA on Ni\{100\} for 1 min at $180 \mathrm{~K}(0.22 \mathrm{ML})$ and annealing to $250 \mathrm{~K}(0.21 \mathrm{ML})$. (The corresponding XPS data are available in the Supporting Information.) The experimentally determined coverage of 0.21 ML is close to the estimated saturation coverage of 0.17 ML. However, the presence of small peaks at $288.2 \mathrm{eV}$ and $289.2 \mathrm{eV}$ in the $\mathrm{C}$ 1s region indicate that there is a small number of molecules adsorbed in the second layer which are not part of the chemisorbed layer.

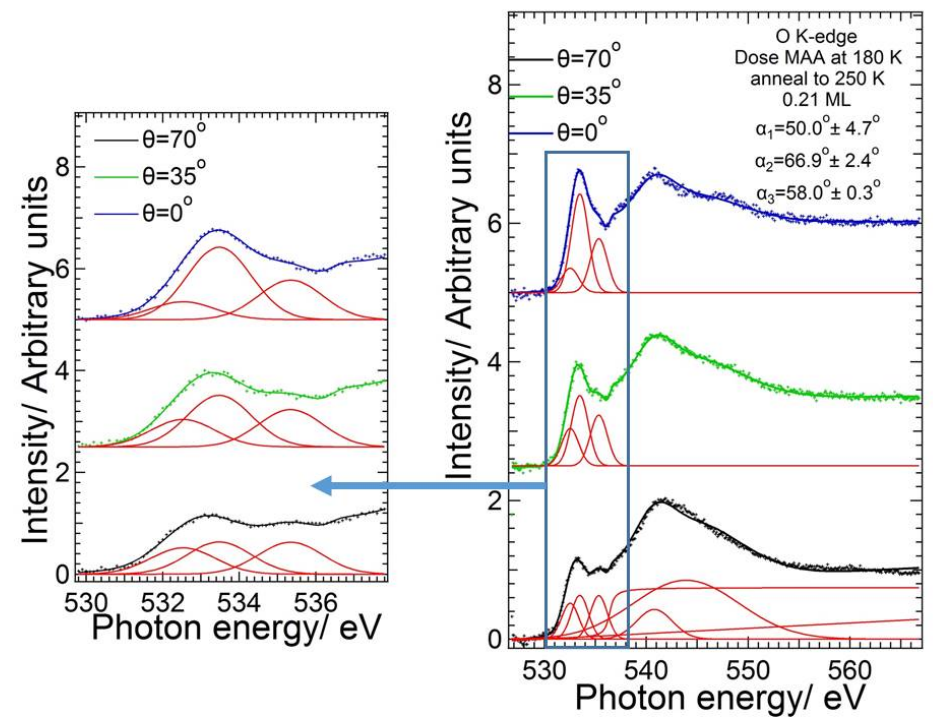

Figure 4: Angle resolved O K-edge NEXAFS spectra after dosing MAA onto Ni\{100\} at $180 \mathrm{~K}$ for $1 \mathrm{~min}$ and annealing the layer to $250 \mathrm{~K}(0.21 \mathrm{ML})$. The dots represent the raw data and the solid lines the fitted curves. The red curves below the spectra indicate the individual Gaussian peaks, linear background, and the step function used for fitting. Right panel: complete spectra; Left panel: energy range of $\pi^{*}$ resonances.

The NEXAFS spectra show a strong $\pi^{*}$ resonance feature around $533.4 \mathrm{eV}$, a step at $536.4 \mathrm{eV}$ and two $\sigma^{*}$ resonances around $541 \mathrm{eV}$ and $544 \mathrm{eV}$. The NEXAFS spectra were fitted using a linear background, a step function and Gaussian peaks representing the $\sigma^{*}$ and $\pi^{*}$ resonances of the molecule (for details see Supporting Information). The individual components of each function used for fitting the spectra are shown as red lines in Figure 4 for each spectrum. The strong $\pi^{*}$ resonance feature consists of three peaks at $532.5 \mathrm{eV}$, $533.5 \mathrm{eV}$ and $535.3 \mathrm{eV}$. The intensities of these peaks show strong angular dependence, which 
allows determining the molecular tilt angle using the procedure described in Ref. ${ }^{52}$ (see also Supporting Information). The values of tilt angles, $\alpha$, with respect to the surface plane, are $50.0^{\circ}, 66.9^{\circ}$ and $58.0^{\circ}$ for the peaks at $532.5 \mathrm{eV}, 533.5 \mathrm{eV}, 535.3 \mathrm{eV}$, respectively. The error margins stated in Figure 4 refer to the fitting error. The two $\sigma^{*}$ resonances can be assigned to $\mathrm{C}-\mathrm{C}$ and $\mathrm{C}-\mathrm{O}$ bonds respectively. ${ }^{15,51}$
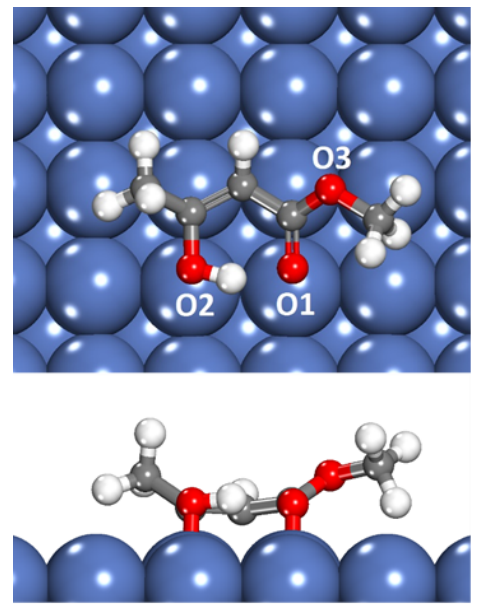

(a) flat enol
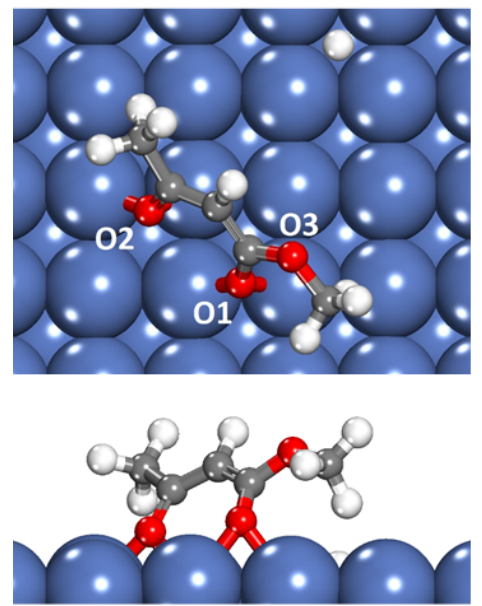

(b) bidentate enolate

Figure 5: Top and side views of the two lowest-energy configurations found by DFT for the adsorption of MAA on the $\mathrm{Ni}\{100\}$ surface: (a) flat enol and (b) bidentate enolate (b); red $=\mathrm{O}$, gray $=\mathrm{C}$, white $=\mathrm{H}$, blue $=\mathrm{Ni}$. 


\section{DFT results}

MAA belongs to the class of $\beta$-diketones of the type $\mathrm{R}-\mathrm{C}(\mathrm{O})-\mathrm{CH}_{2}-\mathrm{C}(\mathrm{O})-\mathrm{R}$. The keto-enol tautomerism of these compounds depends strongly on the substituent R. Symmetrically substituted $\beta$-diketones exist in the enol tautomeric form $\mathrm{R}-\mathrm{C}(\mathrm{OH})-\mathrm{CH}-\mathrm{C}(\mathrm{O})-\mathrm{R}$ when $\mathrm{R}$ is $\mathrm{CH}_{3}$, and in the diketo tautomeric form $\mathrm{R}-\mathrm{C}(\mathrm{O})-\mathrm{CH}_{2}-\mathrm{C}(\mathrm{O})-\mathrm{R}$ when $\mathrm{R}$ is $\mathrm{OCH}_{3} \cdot{ }^{53}$ Both substituents are present in MAA, making its tautomeric behavior interesting: MAA vapor at $309 \mathrm{~K}$ exhibits a composition of $80 \%$ enol and $20 \%$ diketo form, ${ }^{54}$ whereas liquid MAA at room temperature exists exclusively in the diketo form. ${ }^{55}$ In our previous work we found that DFT predicts the enol configuration as the most stable tautomer of MAA in the gas phase. ${ }^{11}$ The diketo tautomer of MAA in its most stable configuration was found to be $0.24 \mathrm{eV}$ above the enol ground state. Because the enol form is the most stable tautomer, we use it as the reference for the calculation of adsorption energies (Equation 1) regardless of the mode of adsorption. As mentioned before, we considered both tautomeric forms of MAA when testing adsorption geometries on the $\mathrm{Ni}\{100\}$ surface, however, the candidates with the MAA in its diketo form were less stable by at least $0.8 \mathrm{eV}$ compared to the two most stable enol species shown in Figure 5. (The other candidate structures are shown in Figure S2 of the Supporting Information)

The first local minimum corresponds to the flat enol configuration shown in Figure 5.a. The main molecular plane formed by the three carbons C2-C1-C3 (see Fig. 1 for numbering) is parallel to the surface with both oxygen atoms from the carbonyl groups (O1 and O2) above atop sites. Unlike in the gas phase, the methyl and methoxy groups are not within this plane but bent away from the surface. The second global minimum (Fig. 5.b) corresponds to the bidentate enolate configuration, where $\mathrm{O} 2$ is deprotonated and the molecular plane is tilted with respect to the Ni surface. The surface bond is formed via the carbonyl groups sited located on bridge sites of non-adjacent rows. The dissociated hydrogen atom is adsorbed elsewhere on the surface on a four-hollow site. In this case, the methyl and methoxy groups remain aligned to the plane of the molecule. The calculated adsorption energies without 
Table 1: Key geometrical and spectroscopic parameters of the two candidate structures found by DFT.

\begin{tabular}{lrr}
\hline & flat enol & \multicolumn{1}{c}{$\begin{array}{c}\text { bidentate } \\
\text { enolate }\end{array}$} \\
\hline$E_{\text {ads }}^{\mathrm{DFT}}$ & $-1.91 \mathrm{eV}$ & $-1.82 \mathrm{eV}$ \\
$E_{\text {ads }}^{\mathrm{DFF}+\mathrm{ZPE}}$ & $-1.97 \mathrm{eV}$ & $-2.02 \mathrm{eV}$ \\
$d(\mathrm{C} 4-\mathrm{O} 3)$ & $1.447 \AA$ & $1.447 \AA$ \\
$d(\mathrm{C} 2-\mathrm{O} 3)$ & $1.367 \AA$ & $1.353 \AA$ \\
$d(\mathrm{C} 2-\mathrm{O} 1)$ & $1.322 \AA$ & $1.284 \AA$ \\
$d(\mathrm{C} 1-\mathrm{C} 2)$ & $1.467 \AA$ & $1.426 \AA$ \\
$d(\mathrm{C} 1-\mathrm{C} 3)$ & $1.461 \AA$ & $1.387 \AA$ \\
$d(\mathrm{C} 3-\mathrm{O} 2)$ & $1.423 \AA$ & $1.331 \AA$ \\
$d(\mathrm{C} 3-\mathrm{C} 5)$ & $1.507 \AA$ & $1.498 \AA$ \\
$d(\mathrm{O} 1-\mathrm{Ni})$ & $2.014 \AA$ & $2.093 \AA$ \\
$d(\mathrm{O} 2-\mathrm{Ni})$ & $2.071 \AA$ & $2.039 \AA / 2.134 \AA$ \\
$\angle \mathrm{C} 2-\mathrm{O} 1-\mathrm{surface}$ & $0.0^{\circ}$ & $49.1^{\circ}$ \\
$\angle \mathrm{C} 3-\mathrm{O} 2-\mathrm{surface}$ & $0.7^{\circ}$ & $53.2^{\circ}$ \\
$\angle \mathrm{C} 2-\mathrm{C} 1-\mathrm{C} 3-$ surface & $8.9^{\circ}$ & $54.3^{\circ}$ \\
$\Delta z(\mathrm{C})$ & $1.118 \AA$ & $0.640 \AA$ \\
$\Delta B E_{\mathrm{O} 1 \mathrm{~s}}(\mathrm{O} 1)$ & $0.00 \mathrm{eV}$ & $0.29 \mathrm{eV}$ \\
$\Delta B E_{\mathrm{O} 1 \mathrm{~s}}(\mathrm{O} 2)$ & $1.29 \mathrm{eV}$ & $0.00 \mathrm{eV}$ \\
$\Delta B E_{\mathrm{O} 1 \mathrm{~s}}(\mathrm{O} 3)$ & $1.63 \mathrm{eV}$ & $1.86 \mathrm{eV}$ \\
\hline
\end{tabular}

$\Delta z(\mathrm{C})$ is the maximum vertical height difference of the molecule's carbon atoms.

vibrational contributions are $-1.91 \mathrm{eV}$ for the flat enol and $-1.82 \mathrm{eV}$ for the bidentate enolate configuration. When vibrational contributions are included, the change in zeropoint energy (ZPE) between gas phase and the adsorbed species stabilizes the bidentate enolate by $-0.20 \mathrm{eV}$ but the flat enol only by $-0.06 \mathrm{eV}$. This result is expected as the number of intra-molecular bonds in the latter is the same as in the gas-phase molecule, whereas with the enolate deprotonation occurs and the adsorbed species has one bond less. 
This extra stabilization yields a total adsorption energy (including electronic and vibrational contributions) of $-2.02 \mathrm{eV}$ for the bidentate enolate configuration compared to $-1.97 \mathrm{eV}$ for the flat enol, hence rendering the enolate more stable.

\section{Discussion}

\section{Comparison of Modelling and Experimental Data}

In order to test whether the bidentate enolate conformation is indeed the predominant mode of adsorption, we compare the experimental XPS data with simulated spectra for the two candidate adsorption configurations. Core-level shifts for the $\mathrm{O}$ 1s photoemission peaks were calculated according to Equation 2. The results are summarized in Table 1 together with some key geometrical data. For both adsorption geometries the BE shifts split into two groups, around $\Delta B E_{\mathrm{O} 1 \mathrm{~s}}=0.00-0.29 \mathrm{eV}$ and $\Delta B E_{\mathrm{O} 1 \mathrm{~s}}=1.29-1.86 \mathrm{eV}$. For the flat enol conformation the oxygen of the carboxylic group (O1) falls into the lower BE group and the oxygen atoms of the hydroxyl and methoxy groups (O2 and O3) into the higher BE group. In the bidentate enolate configuration, the two oxygen atoms of the carboxylic groups (O1 and $\mathrm{O} 2$ ) have low BE and the methoxy oxygen (O3) has high BE.

For a further comparison with the experimental O 1s XPS data, spectra were modelled by the superposition of Gaussian functions of the same height, positioned according to the calculated BE shifts for each oxygen atom of the flat enol and bidentate enolate configurations (cf Table 1). A width (FWHM) of $1.5 \mathrm{eV}$ was used for each Gaussian, which was determined by fitting the experimental data and is in accordance with our earlier work. ${ }^{11}$ Figure 6 shows the individual Gaussians and their superposition alongside the experimental $O$ is spectrum of MAA after annealing to $340 \mathrm{~K}$. At this temperature, the coverage is $0.16 \mathrm{ML}$, close to the estimated saturation coverage of chemisorbed MAA on $\mathrm{Ni}\{100\}$ (0.17 ML). The coverage is different from the one used in the DFT calculations (0.04 ML), however strong lateral interaction, such as hydrogen bonding is not expected for MAA, therefore the 
adsorption geometry for chemisorbed molecules should be largely independent of coverage. The BE scale of the theoretical spectra has been shifted such that they coincide with the experimental data. Clearly, the simulated spectrum of the bidentate enolate conformation is in much better quantitative agreement with the experimental data than the one of the flat enol. Both the energy separation, $1.6 \mathrm{eV}$, and the relative heights of the two peaks fit the experimental data very well. As mentioned before in the Results Section, the intensity ratio between the low $\mathrm{BE}$ and high $\mathrm{BE}$ peaks ( $\mathrm{A}$ and $\mathrm{B}$ ) is close to $2: 1$, in the experimental spectrum for this layer, which suggests that MAA at this coverage is chemisorbed on $\mathrm{Ni}\{100\}$ in a bidentate form, through its two oxygens, as in the bidentate enolate configuration.

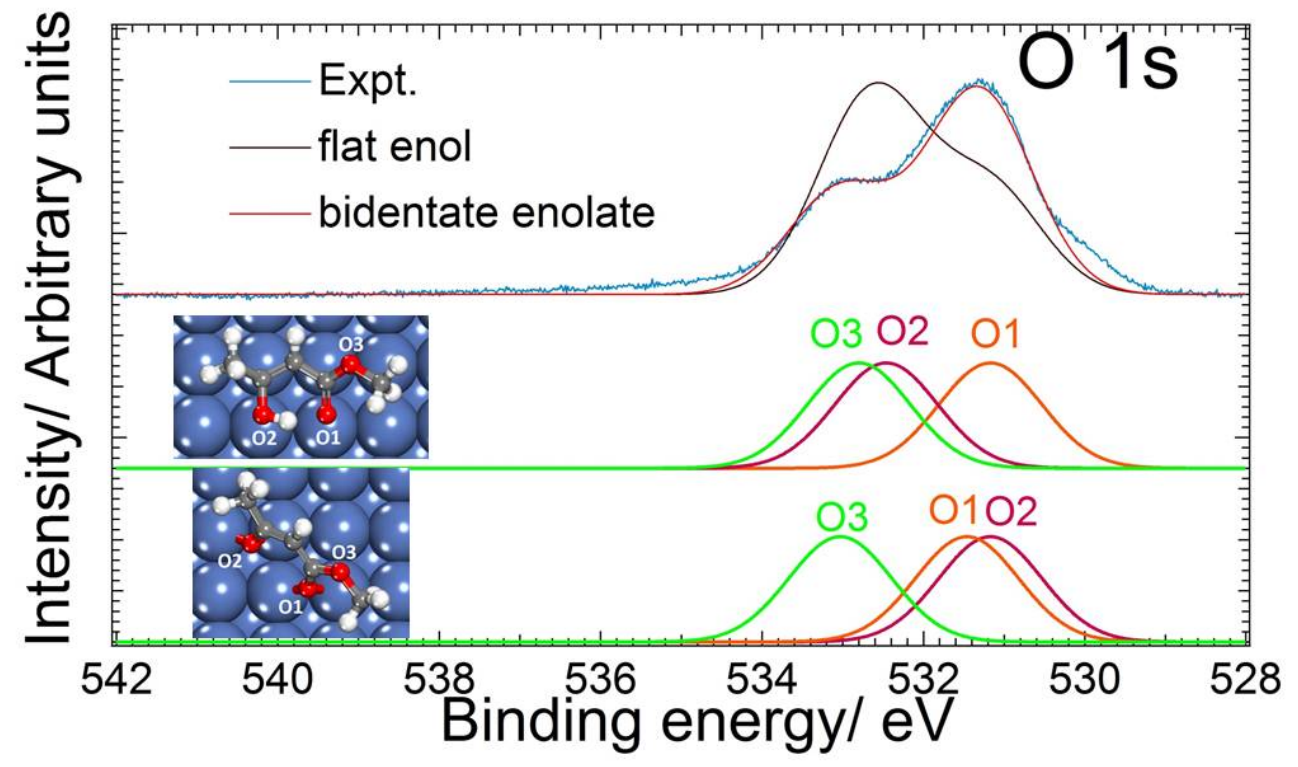

Figure 6: Comparison of experimental XPS data obtained after annealing the MAA layer to $340 \mathrm{~K}(0.16 \mathrm{ML})$ and modelled XPS spectra of the flat enol and bidentate enolate configurations. Top: direct comparison of experimental and modelled spectra; middle: individual Gaussian peaks centered at the calculated core level shifts for the flat enol; bottom: individual Gaussian peaks centered at the calculated core level shifts for the bidentate enolate.

Additional confirmation for the bidentate enolate adsorption geometry comes from the NEXAFS data. The DFT-optimised geometry predicts the molecular plane being tilted with respect to the surface plane. The inclination angles for the $\mathrm{C}-\mathrm{O}$ bonds are $\angle \mathrm{C} 3 \mathrm{O} 2=53.2^{\circ}$ 
and $\angle \mathrm{C} 2 \mathrm{O} 1=49.1^{\circ}$; the plane of the carbon backbone has an angle of $\angle \mathrm{C} 1 \mathrm{C} 2 \mathrm{C} 3=54.3^{\circ}$ with respect to the surface (cf Tab. 1).

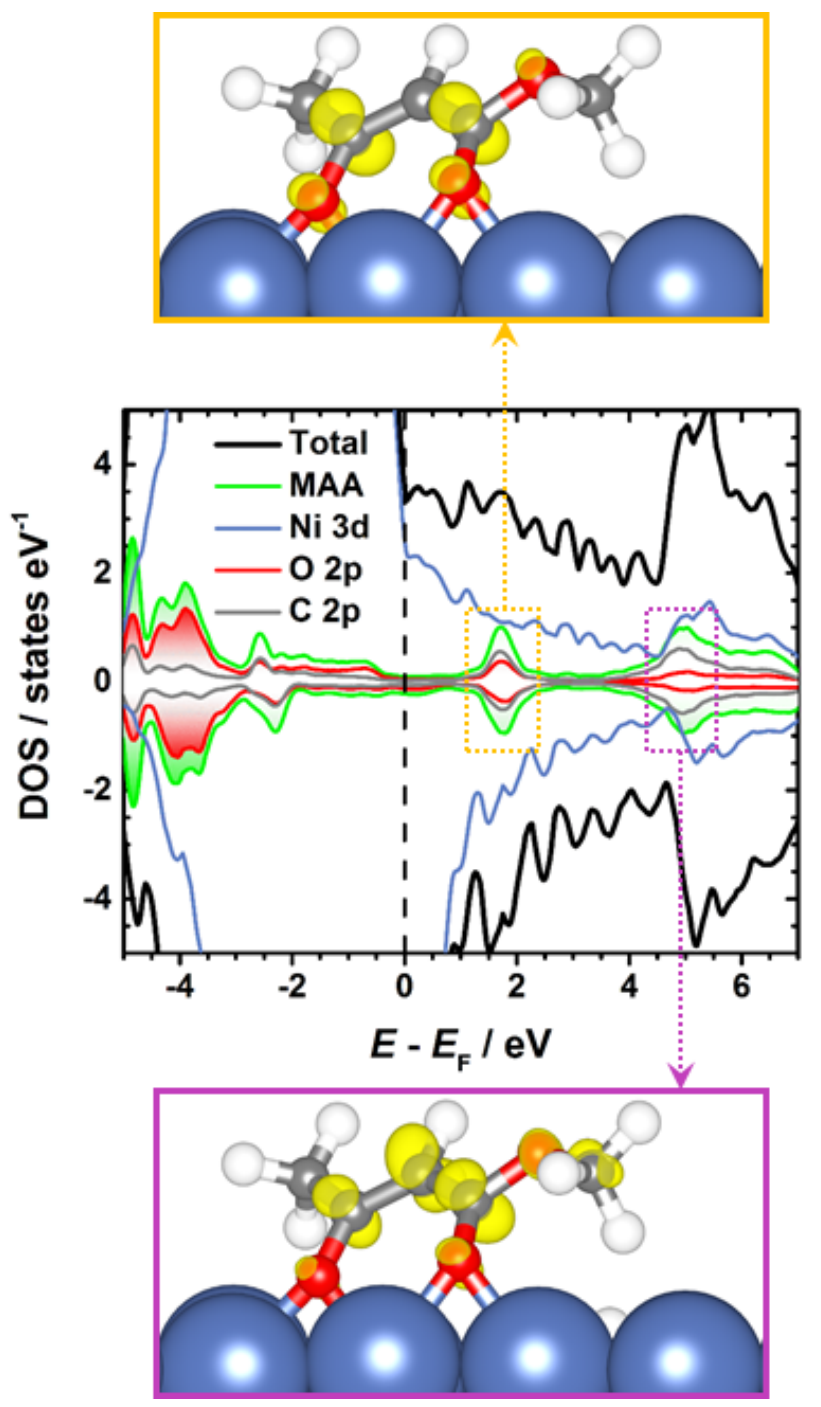

Figure 7: Electronic density of states (DOS) of the bidentate enolate conformation (center). The vertical dashed line marks the Fermi level $\left(E_{\mathrm{F}}\right)$. The charge density isosurfaces, corresponding to electronic states with energies between 1.28 and $2.22 \mathrm{eV}$ (top) and 4.38 and $5.32 \mathrm{eV}$ (bottom) above the Fermi level, are highlighted with dotted rectangles.

The NEXAFS spectra consist of three peaks in the $\pi^{*}$-resonance region, at $532.5 \mathrm{eV}$, $533.5 \mathrm{eV}$, and $535.3 \mathrm{eV}$ (Fig. 4), which are most likely associated with these bonds, as they all are expected to be part of a resonant $\pi$-system. In order to make the correlation between the molecular geometry and these resonances, the density of states (DOS) near the Fermi energy was calculated for the bidentate enolate adsorption complex. Figure 7 shows the total 
DOS (black line), the DOS associated with the molecule (green), and the projections onto the Ni 3d, O 2p, C 2p states (blue, red, grey).

The Figure clearly shows a high density of empty states in the vicinity of $\mathrm{C}$ and $\mathrm{O}$ atoms around $1.7 \mathrm{eV}$ and $4.8 \mathrm{eV}$ above the Fermi level, which are associated with resonant $\pi$-like orbitals extending over most of the molecule. The main contribution to the states at $1.7 \mathrm{eV}$ above the Fermi level are near the C3-O2 and C2-O1 bonds pointing towards the surface (see top panel of Figure 7), while the empty states at $4.8 \mathrm{eV}$ are located near the plane formed by C2,C1, and C3 (bottom panel of Fig. 7). The energy difference between the two DOS maxima $(\sim 3.1 \mathrm{eV})$ is very close to the energy difference between peak $1(532.5 \mathrm{eV})$ and peak $3(535.3 \mathrm{eV})$ in the NEXAFS spectra; we therefore assign the NEXAFS peaks 1 and 2 at $532.5 \mathrm{eV}$ and $533.5 \mathrm{eV}$, respectively, to $\pi$-like orbital states associated with $\mathrm{C}-\mathrm{O}$ bonds, while the peak at $535.33 \mathrm{eV}$ is linked to the $(\mathrm{C} 2 \mathrm{C} 1 \mathrm{C} 3)$ plane. The angles derived from the angular dependence of peaks 1 and 2 are $50.0^{\circ}$ and $66.9^{\circ}$ which is in fair agreement with the values from the DFT geometry $\left(53.2^{\circ}\right.$ and $\left.49.1^{\circ}\right)$. The angle derived from the high photon energy peak $3(535.33 \mathrm{eV})$ is $58^{\circ}$ which also close to the theoretical value $54.3^{\circ}$ for the angle of the $(\mathrm{C} 2 \mathrm{C} 1 \mathrm{C} 3)$ plane. A closer look at the top and bottom panel of Figure 7 shows that the respective orbitals are not exclusively associated with only one bond. Therefore, the angular dependence of the NEXAFS resonances, which is determined by the orientation of orbitals rather than bonds, must be expected to deviate somewhat from the bond orientation. However, the experimental values are clearly not compatible with the flat enol adsorption complex where the molecular plane is essentially parallel to the surface (tilt angles between $0.0^{\circ}$ and $8.9^{\circ}$, see Tab. 1$)$.

Based on the above comparison of experimental and computational results we can confidently state that MAA adsorbs on $\mathrm{Ni}\{100\}$ in a bidentate enolate geometry. It should be stressed, that the small energy difference between the enolate and the enol adsorption species would not allow an unambiguous discrimination on the basis of DFT alone. Only the comparison with experimentally determined parameters, such as tilt angles and chemical 
shifts in XPS make a reliable determination of the adsorption complex possible.

\section{Implications for Heterogeneous Catalysis}

The TP-XPS experiments in this work show the onset of the decomposition of MAA on $\mathrm{Ni}\{100\}$ around $300-330 \mathrm{~K}$; the molecule is fully decomposed at temperatures greater than $350 \mathrm{~K}$. This decomposition temperature is within the temperature range of $273 \mathrm{~K}$ to $373 \mathrm{~K}$ typically used in enantioselective catalysis. ${ }^{1,8}$ In contrast, TP-XPS and step annealing experiments for MAA on $\mathrm{Ni}\{111\}$, carried out under similar conditions, find the onset of decomposition at a significantly lower temperature of $270 \mathrm{~K}$, but the decomposition process proceeds in two steps and is only complete decomposition at around $390 \mathrm{~K} .{ }^{11}$

Earlier TPD experiments by Jones et al. suggested that MAA on Ni\{111\} starts decomposing at $350 \mathrm{~K} .{ }^{28}$ However these experiments involved adsorption at $300 \mathrm{~K}$ (i.e. above the onset of the first decomposition step) and significantly higher heating rates $\left(2 \mathrm{~K} \mathrm{~s}^{-1}\right)$ than in Ref. ${ }^{11}$. It is likely that Jones et al. only observed the second decomposition step. The same study also shows a delayed onset of decomposition when MAA is co-adsorbed with tartaric acid on $\mathrm{Ni}\{111\}$. This indicates that the interaction with modifier molecules has a stabilising effect under reaction conditions, which is most likely also the case on $\mathrm{Ni}\{100\}$. Nevertheless, it appears that the reactant MAA is intact over the range of typical reaction temperatures only on the $\mathrm{Ni}\{100\}$ surface, and not on $\mathrm{Ni}\{111\}$.

The tilted bidentate enolate geometry found here is similar to the geometry found for MAA on $\mathrm{Ni}\{111\}$ earlier. ${ }^{11}$ The most stable adsorption complex of MAA on $\mathrm{Ni}\{100\}$ is a enolate $(=\mathrm{C} 1 \mathrm{H}---)$, whereas all diketo candidate structures $\left(-\mathrm{C}_{1} \mathrm{H}_{2}-\right)$ tested in this study were found to be much less stable. Only the flat enol structure is similar in energy, but could be excluded by comparison with experimental data. The tilted adsorption geometry of the bidentate enolate offers an obvious mechanism for enentio-selective hydrogenation. If we assume that the dissociation of $\mathrm{H}_{2}$ takes place on the Ni surface, it will be more likely for the hydrogen atoms to attach to the molecule on the side that is tilted towards the surface. 
On an unmodified $\mathrm{Ni}\{100\}$ surface, which has a mirror symmetry, the tilt can be in both directions. The role of a modifier is, therefore, to break the mirror symmetry and stabilise only one of two possible tilt directions. A similar mechanism would also explain enantioselectivity for the flat enol geometry or di-keto structures that break the mirror symmetry of the surface in a similar way. Indeed, both enol and diketo conformers of MAA lead to enantioselective products, as a series of IR absorption studies has confirmed recently, ${ }^{10,21}$ which investigated MAA on glutamic-acid-modified $\mathrm{Ni}\{111\}$ model catalysts under similar conditions as earlier experiments on Raney-nickel catalysts described by Izumi. ${ }^{1}$ When the surface is modified with (S)-glutamic acid the enol(ate) tautomer leads to the (S)-methyl3-hydroxybutyrate product and the di-keto form to the $(\mathrm{R})$ product. When glutamic acid is used as modifier, the modification conditions ( $\mathrm{pH}$ and temperature) have an influence on whether MAA assumes the enol or diketo conformer. Further studies with co-adsorbed reactant and modifier molecules will be necessary to determine the exact geometry of the modifier-MAA complex at the molecular level and establish the reaction mechanism that leads to the chiral product formation.

\section{Summary}

In summary, we have carried out a combined experimental and theoretical study of the interaction of MAA with the $\mathrm{Ni}\{100\}$ surface using XPS, NEXAFS, and DFT. The desorption of the multilayer MAA occurs at 200-220 K, leaving behind a stable chemisorbed layer which starts decomposing at 300-330 $\mathrm{K}$ and is completely dissociated at $\sim 350 \mathrm{~K}$.

DFT calculations predict that the chemisorbed layer consists of a deprotonated enolate species with a tilted bidentate surface bond through two oxygen atoms. The enolate conformer and the tilt angle between $49.1^{\circ}$ and $54.3^{\circ}$ with respect to the surface plane is confirmed by comparison with spectroscopic data. A non-deprotonated enol tautomer is less stable by $50 \mathrm{meV}$, when vibrational zero-point energy contributions are taken into account. 
All diketo candidate structures were found to be significantly less stable.

\section{Supporting Information Available}

The following files are available free of charge.

- Ni111_MAA_SI.pdf: complete list of model geometries studied by DFT; details of NEXAFS data analysis; additional XPS spectra.

- flat_enol.xyz, bidentate_enolate.xyz: complete set of coordinates for the flat enol and the bidentate enolate adsorption complexes.

\section{Acknowledgement}

J.O. acknowledges funding from Ecuador Government's agency SENESCYT in the form of a Ph.D. studentship award (CA-2012-2). The authors thank the staff of Elettra for their help during the experiments, in particular Silvano Lizzitand Paolo Lacovig. This work made use of ARCHER, the U.K.'s national high-performance computing service, via the U.K.'s HPC Materials Chemistry Consortium, which is funded by EPSRC (EP/L000202). 


\section{References}

(1) Izumi, Y. Modified Raney nickel (MRNi) catalyst: Heterogeneous enantiodifferentiating (asymmetric) catalyst. Adv. Catal. 1983, 32, 215-271.

(2) Webb, G.; Wells, P. Asymmetric hydrogenation. Catal. Today 1992, 12, 319-337.

(3) Baiker, A. Progress in asymmetric heterogeneous catalysis: Design of novel chirally modified platinum metal catalysts. J. Mol. Catal. A Chem. 1997, 115, 473-493.

(4) Baiker, A. Transition state analogues - a guide for the rational design of enantioselective heterogeneous hydrogenation catalysts. J. Mol. Catal. A Chem. 2000, 163, 205-220.

(5) Baddeley, C.; Held, G. In Comprehensive Nanoscience and Technology; Andrews, D., Scholes, G., Wiederrecht, G., Eds.; Elsevier: Amsterdam, 2010; pp 105-133.

(6) Baddeley, C. J.; Jones, T. E.; Trant, A. G.; Wilson, K. E. Fundamental investigations of enantioselective heterogeneous catalysis. Top. Catal. 2011, 54, 1348-1356.

(7) Sharpless, K. B. Searching for new reactivity (Nobel Lecture). Angew. Chemie Int. Ed. 2002, 41, 2024-2032.

(8) Keane, M. A. Adsorption of optically pure alanine on silica-supported nickel and the consequent catalytic enantioselectivity. Langmuir 1994, 10, 4560-4565.

(9) Keane, M. A. Interaction of optically active tartaric acid with a nickel-silica catalyst: Role of both the modification and reaction media in determining enantioselectivity. Langmuir 1997, 13, 41-50.

(10) Jones, T.; Rekatas, A. E.; Baddeley, C. J. Influence of modification pH and temperature on the interaction of methylacetoacetate with $(S)$-glutamic acid-modified Ni $\{111\} . J$. Phys. Chem. C 2007, 111, 5500-5505. 
(11) Ontaneda, J.; Nicklin, R. E. J.; Cornish, A.; Roldan, A.; Grau-Crespo, R.; Held, G. Adsorption of methyl acetoacetate at $\mathrm{Ni}\{111\}$ : Experiment and theory. J. Phys. Chem. C 2016, 120, 27490-27499.

(12) Humblot, V.; Haq, S.; Muryn, C.; Hofer, W. A.; Raval, R. From local adsorption stresses to chiral surfaces: $(R, R)$-tartaric acid on Ni(110). J. Am. Chem. Soc. 2002, 124, 503-510.

(13) Humblot, V.; Haq, S.; Muryn, C.; Raval, R. $(R, R)$-Tartaric acid on Ni(110): the dynamic nature of chiral adsorption motifs. J. Catal. 2004, 228, 130-140.

(14) Hofer, W.; Humblot, V.; Raval, R. Conveying chirality onto the electronic structure of achiral metals: $(R, R)$-tartaric acid on nickel. Surf. Sci. 2004, 554, 141-149.

(15) Nicklin, R. E. J.; Cornish, A.; Shavorskiy, A.; Baldanza, S.; Schulte, K.; Liu, Z.; Bennett, R. A.; Held, G. Surface chemistry of alanine on Ni\{111\}. J. Phys. Chem. C 2015, $119,26566-26574$.

(16) Shavorskiy, A.; Eralp, T.; Schulte, K.; Bluhm, H.; Held, G. Surface chemistry of glycine on $\operatorname{Pt}\{111\}$ in different aqueous environments. Surf. Sci. 2013, 607, 10-19.

(17) Eralp, T.; Shavorskiy, A.; Held, G. The adsorption geometry and chemical state of lysine on $\mathrm{Cu}\{110\}$. Surf. Sci. 2011, 605, 468-472.

(18) Eralp, T.; Ievins, A.; Shavorskiy, A.; Jenkins, S. J.; Held, G. The importance of attractive three-point interaction in enantioselective surface chemistry: Stereospecific adsorption of serine on the intrinsically chiral $\mathrm{Cu}\{531\}$ surface. J. Am. Chem. Soc. 2012, 134, 9615-9621.

(19) Baldanza, S.; Cornish, A.; Nicklin, R. E.; Zheleva, Z. V.; Held, G. Surface chemistry of alanine on $\mathrm{Cu}\{111\}$ : Adsorption geometry and temperature dependence. Surf. Sci. 2014, 629, 114-122. 
(20) Jones, T.; Urquhart, M.; Baddeley, C. An investigation of the influence of temperature on the adsorption of the chiral modifier, $(S)$-glutamic acid, on Ni\{111\}. Surf. Sci. 2005, 587, 69-77.

(21) Jones, T.; Baddeley, C. J. Investigating the mechanism of chiral surface reactions: the interaction of methylacetoacetate with (S)-glutamic acid modified $\mathrm{Ni}\{111\}$. Langmuir 2006, 22, 148-52.

(22) Ghiringhelli, L. M.; Schravendijk, P.; Delle Site, L. Adsorption of alanine on a Ni(111) surface: A multiscale modeling oriented density functional study. Phys. Rev. B 2006, 74,035437 .

(23) Barlow, S.; Raval, R. Complex organic molecules at metal surfaces: bonding, organisation and chirality. Surf. Sci. Rep. 2003, 50, 201-341.

(24) Held, G.; Gladys, M. J. The chemistry of intrinsically chiral surfaces. Top. Catal. 2008, 48, 128-136.

(25) Mahapatra, M.; Tysoe, W. T. Structure and decomposition pathways of D-(-)-tartaric acid on $\operatorname{Pd}(111)$. Surf. Sci. 2014, 629, 132-138.

(26) Mahapatra, M.; Burkholder, L.; Devarajan, S. P.; Boscoboinik, A.; Garvey, M.; Bai, Y.; Tysoe, W. T. Formation of induced-fit chiral templates by amino acid-functionalized Pd(111) Surfaces. J. Phys. Chem. C 2015, 119, 3556-3563.

(27) Jones, T.; Baddeley, C. A RAIRS, STM and TPD study of the Ni $\{111\} / R, R$-tartaric acid system: Modelling the chiral modification of Ni nanoparticles. Surf. Sci. 2002, $513,453-467$.

(28) Jones, T.; Baddeley, C. Direct STM evidence of a surface interaction between chiral modifier and pro-chiral reagent: Methylacetoacetate on $R, R$-tartaric acid modified Ni\{111\}. Surf. Sci. 2002, 519, 237-249. 
(29) Jones, T.; Baddeley, C. An investigation of the adsorption of $(R, R)$-tartaric acid on oxidised Ni\{111\} surfaces. J. Mol. Catal. A Chem. 2004, 216, 223-231.

(30) Lauterbach, J.; Wittmann, M.; Küppers, J. Adsorption of CO at Ni(100) surfaces: a FTIRAS - TDS study. Surf. Sci. 1992, 279, 287-296.

(31) Stöhr, J. NEXAFS spectroscopy; Springer series in Surface Sciences; Springer: Berlin, 1996.

(32) Kresse, G.; Furthmüller, J. Efficiency of ab-initio total energy calculations for metals and semiconductors using a plane-wave basis set. Comput. Mater. Sci. 1996, 6, 15-50.

(33) Kresse, G.; Furthmüller, J. Efficient iterative schemes for ab initio total-energy calculations using a plane-wave basis set. Phys. Rev. B 1996, 54, 11169-11186.

(34) Mohsenzadeh, A.; Bolton, K.; Richards, T. DFT study of the adsorption and dissociation of water on $\mathrm{Ni}(111), \mathrm{Ni}(110)$ and $\mathrm{Ni}(100)$ surfaces. Surf. Sci. 2014, 627, 1-10.

(35) Mohsenzadeh, A.; Richards, T.; Bolton, K. DFT study of the water gas shift reaction on $\mathrm{Ni}(111), \mathrm{Ni}(100)$ and $\mathrm{Ni}(110)$ surfaces. Surf. Sci. 2016, 644, 53-63.

(36) Wang, S. G.; Cao, D. B.; Li, Y. W.; Wang, J.; Jiao, H. Chemisorption of $\mathrm{CO}_{2}$ on nickel surfaces. J. Phys. Chem. B 2005, 109, 18956-18963.

(37) O’Rourke, C.; Bowler, D. R. DSSC anchoring groups: A surface dependent decision. J. Phys. Condens. Matter 2014, 26, 44.

(38) Tillotson, M. J.; Brett, P.; Bennett, R. A.; Grau-Crespo, R. Adsorption of organic molecules at the $\mathrm{TiO}_{2}(110)$ surface: the effect of van der Waals interactions. Surf. Sci. 2015, 632, 142-153.

(39) Blöchl, P. E. Projector augmented-wave method. Phys. Rev. B 1994, 50, 17953-17979. 
(40) Kresse, G.; Joubert, D. From ultrasoft pseudopotentials to the projector augmentedwave method. Phys. Rev. B 1999, 59, 1758-1775.

(41) Monkhorst, H. J.; Pack, J. D. Special points for Brillouin-zone integrations. Phys. Rev. $B$ 1976, 13, $5188-5192$.

(42) Makov, G.; Payne, M. Periodic boundary conditions in ab initio calculations. Phys. Rev. B 1995, 51, 4014-4022.

(43) Zhang, Y.; Yang, W. Comment on "Generalized gradient approximation made simple". Phys. Rev. Lett. 1998, 80, 890-890.

(44) Grimme, S.; Antony, J.; Ehrlich, S.; Krieg, H. A consistent and accurate ab initio parametrization of density functional dispersion correction (DFT-D) for the 94 elements H-Pu. J. Chem. Phys. 2010, 132, 154104.

(45) Grimme, S.; Ehrlich, S.; Goerigk, L. Effect of the damping function in dispersion corrected density functional theory. J. Comput. Chem. 2011, 32, 1456-65.

(46) Goerigk, L.; Grimme, S. A thorough benchmark of density functional methods for general main group thermochemistry, kinetics, and noncovalent interactions. Phys. Chem. Chem. Phys. 2011, 13, 6670-88.

(47) Birgersson, M.; Almbladh, C.-O.; Borg, M.; Andersen, J. Density-functional theory applied to $\mathrm{Rh}(111)$ and $\mathrm{CO} / \mathrm{Rh}(111)$ systems: Geometries, energies, and chemical shifts. Phys. Rev. B 2003, 67, 045402.

(48) Köhler, L.; Kresse, G. Density functional study of CO on Rh(111). Phys. Rev. B 2004, $70,165405$.

(49) Gotterbarm, K.; Luckas, N.; Höfert, O.; Lorenz, M. P. A.; Streber, R.; Papp, C.; Viñes, F.; Steinrück, H. P.; Görling, A. Kinetics of the sulfur oxidation on palladium: 
A combined in situ x-ray photoelectron spectroscopy and density-functional study. $J$. Chem. Phys. 2012, 136, 094702.

(50) Ontaneda, J.; Bennett, R. A.; Grau-Crespo, R. Electronic structure of Pd multilayers on $\operatorname{Re}(0001)$ : The role of charge transfer. J. Phys. Chem. C 2015, 119, 23436-23444.

(51) Jones, G.; Jones, L. B.; Thibault-Starzyk, F.; Seddon, E. A.; Raval, R.; Jenkins, S. J.; Held, G. The local adsorption geometry and electronic structure of alanine on $\mathrm{Cu}\{110\}$. Surf. Sci. 2006, 600, 1924-1935.

(52) Stöhr, J.; Outka, D. A. Determination of molecular orientations on surfaces from the angular dependence of near-edge x-ray-absorption fine-structure spectra. Phys. Rev. B 1987, 36, 7891-7905.

(53) Belova, N. V.; Sliznev, V. V.; Oberhammer, H.; Girichev, G. V. Tautomeric and conformational properties of $\beta$-diketones. J. Mol. Struct. 2010, 978, 282-293.

(54) Belova, N. V.; Oberhammer, H.; Girichev, G. V. Tautomeric and conformational properties of methyl acetoacetate, $\mathrm{CH}_{3} \mathrm{OC}(\mathrm{O})-\mathrm{CH}_{2}-\mathrm{C}(\mathrm{O}) \mathrm{CH}_{3}$ : electron diffraction and quantum chemical study. J. Phys. Chem. A 2004, 108, 3593-3597.

(55) Schiavoni, M. M.; Di Loreto, H. E.; Hermann, A.; Mack, H. G.; Ulic, S. E.; Della Vdova, C. O. Keto-enol tautomerism in $\beta$-ketoesters: $\mathrm{CH}_{3} \mathrm{C}(\mathrm{O}) \mathrm{CHXC}(\mathrm{O}) \mathrm{OY}(\mathrm{X}=$ $\mathrm{H}, \mathrm{Cl} ; \mathrm{Y}=\mathrm{CH}_{3}, \mathrm{C}_{2} \mathrm{H}_{5}$ ). Vibrational analyses, NMR spectra and quantum chemical calculations. J. Raman Spectrosc. 2001, 32, 319-329. 


\section{Graphical TOC Entry}

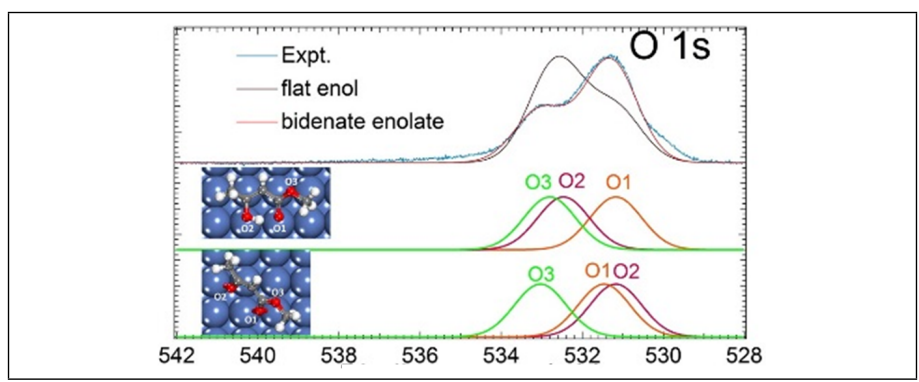

